\title{
Genotyping pathogenic strains of genus Xanthomonas causing bacterioses in a number of plants by DDSL technique
}

\author{
Alexander Lazarev ${ }^{1}$, Valeriy Terletskiy ${ }^{1,2}$, and Vladimir Chebotar ${ }^{3}$ \\ 1Federal State Budget Scientific Institution "All-Russian Institute of Plant Protection", \\ Shosse Podbelskogo, 3, Saint Petersburg, 196608, Russian Federation \\ 2Puskin Leningrad State University, Peterburgskoye Shosse, 10, Saint Petersburg, \\ 196605, Russian Federation \\ ${ }^{3}$ Federal State Budget Scientific Institution "All-Russian Research Institute of Agricultural \\ Microbiology", Shosse Podbelskogo, 3, Saint Petersburg, 196608, Russian Federation
}

Address correspondence and requests for materials to Valeriy Terletskiy, valeriter@mail.ru

Citation: Lazarev, A., Terletskiy, V., and Chebotar, V. 2019. Genotyping pathogenic strains of genus Xanthomonas causing bacterioses in a number of plants by DDSL technique. Bio. Comm. 64(3): 183-188. https://doi.org/10.21638/spbu03.2019.302

Author's information: Alexander Lazarev, $\mathrm{PhD}$, Senior Researcher, orcid.org/00000002-4282-0141; Valery Terletskiy, Dr. of Sci. in Biology, Professor, Head of Laboratory, orcid org/0000-0003-4043-3823; Vladimir Chebotar, PhD, Head of Laboratory, orcid. org/0000-0001-9762-989X

Manuscript Editor: Anton Nizhnikov, Department of Genetics and Biotechnology, Faculty of Biology, Saint Petersburg State University, Saint Petersburg, Russia

Received: June 1, 2019;

Revised: July 4, 2019;

Accepted: July 12, 2019;

Copyright: ( 2019 Lazarev et al. This is an open-access article distributed under the terms of the License Agreement with Saint Petersburg State University, which permits to the authors unrestricted distribution, and self-archiving free of charge.

Funding: The work was supported in sections by: 1 . The state task (Project N 0665-2018-0006). Development of the ecological and genetic basis for the selection of antagonist microbial strains, entomopathogenic fungi and nematodes; development of technologies for the production and use of new multifunctional drugs to control the number of harmful organisms (pests, pathogens) and increase soil suppressiveness. 2 . The comprehensive target program of the Russian Federation "Scientific support for the creation of a domestic sowing fund, products of plant protection for the production of competitive agricultural products by Russian producers, as well as the creation of production technologies (cultivation) and storage of such products for 2016-2025" (according to the priority direction "Potato").

Competing interests: The authors have declared that no competing interests exist.

\section{Abstract}

In the genus Xanthomonas, specialists consider a significant number of species and varieties (pathovars) of phytopathogenic bacteria that infect many agricultural and ornamental plants (about 400 species), which leads to serious economic losses. For the timely detection of these pathogens, accurate diagnosis is necessary, allowing correct and prompt identification. Molecular genetic methods are able to identify populations of Xanthomonas strains with a fairly complete characterization of their hereditary material. The proposed method of genotyping - double digest and selective label (DDSL) - is based on the use of two restriction endonucleases for the separation of bacterial genomic DNA. The DNA polymerase $(\mathrm{Taq})$ present in the reaction mixture along with biotinylated deoxycytosine triphosphate (Bio-dCTP) allows for the visualization of DNA fragments. The tag only labels DNA fragments that have 3'-recessed ends formed by the first enzyme (BCul). The second restriction endonuclease (Eco147I) produces blunt ends that are unable to incorporate the label. As a result, in the DDSL reaction, 20-50 clearly distinguishable DNA fragments are visualized on the filter. The number and distribution of fragments are characteristic for each bacterial strain of the genus Xanthomonas. Genotyping these microorganisms makes it possible to identify the specific profile of each strain, i.e., assign it a sort of "bar code" for individual specification. The strains of bacteria of the genus Xanthomonas, obtained from different species (tomato, radish, sorghum) are genetically separated from each other, showing a specific pattern in terms of the distribution of DNA fragments, despite the common geographical origin. A comparatively rare case of the identity of strains, despite their geographical and temporal unrelatedness and different cultures, has been recorded.

Keywords: Xanthomonas, strain, genotyping, double digest and selective label (DDSL), restriction endonucleases.

\section{Introduction}

The genus Xanthomonas includes about 40 species and varieties (pathovars) of phytopathogenic bacteria affecting a significant number of agricultural and ornamental plants (more than 400 species), which leads to serious economic losses. Some of its species are characterized by the ability to infect a significant number of plants, others are divided into multiple pathovars, the designation of which is associated with confinement to a particular host. Among them, causative agents of vascular bacteriosis of cabbage (X.campestris pv. campestris), black bacterial blotch of tomato (pv. vesicatoria), leaf streaks and black bacteriosis of cereal seeds (pv. translucens), begonia (pv. begoniae), yellow hyacinth disease (pv. hyacinthi) and others are most known and they are characterized by high severity. So, at 
present, the bacterium $X$.campestris pv. vesicatoria is common in more than 70 countries; tomato fruits affected by this pathogen are unsuitable for human consumption, and the proportion of diseased plants in the field can reach $100 \%$. Phytopathogens of the genus Xanthomonas cause vascular necrotization and spotting on many terrestrial parts of the plants. The bacteria are short, gram-negative rods with rounded ends, $1.05-2.4 \times 0.45-0.9 \mu \mathrm{m}$ in size, mobile (with 1-2 polar flagella), aerobic, oxidative-negative, catalase-positive, and possess amylolytic and pectolytic properties. When developing on nutrient media, colonies of mucous consistency are formed, mainly with yellow pigment (Ignatov et al., 2007; Mansfield et al., 2012).

Currently, genotyping plays an important role not only for identifying interspecific features of pathogens of the genus Xanthomonas, but also in differentiating the genetic structure of their individual pathogenic strains at the DNA level (Barak and Gilbertson, 2003; Xiu et al., 2006; Bui et al., 2009; Nabhan et al., 2012; Pritchard et al., 2012). Previous research showed some limitations of individual methods of this testing in recognizing the genetic structure of a population of certain Xanthomonas species (Barak and Gilbertson, 2003). They found that amplification of DNA repeats (rep-PCR) and sequencing of the internal transcribed spacer (ITS1) of ribosomal RNA genes does not allow for the specification of genetic heterogeneity in the analyzed phytopathogenic strains. The differences were established using genotyping based on restriction fragment length polymorphism with a labeled probe and analysis of the plasmid profiles of the bacterium. Studies by Spanish authors (Lopez et al., 2006), who managed to divide the groups of phytopathogens into only two clusters, indicate a low level of discrimination between bacterial strains using the methods of rep-PCR and RAPD, although the strains had a significant geographical distance and it was possible to assume more significant genetic differences between them. The results (Bui T.N. et al., 2009) show that despite the presence of a large number of methods for the testing of bacteria there is still the need to develop new methods for specific pathogens (in particular, members of the genus Xanthomonas). These authors mention the unequal discriminatory ability of restriction fragment amplification methods (AFLP), tandem repeat variability (MLVA) and PCR-genotyping. Testing microorganisms using the MLVA method is widely used to detect certain differences between strains in bacterial populations. Some researchers show low discrimination between epidemiologically unrelated Xanthomonas strains, as determined by AFLP and PCR with random primers (RAPD); the similarity rate in pairwise comparisons of genetic profiles reached $66 \%$ and $80 \%$, respectively, indicating low resolution (Ogunjobi et al., 2010). Other authors point out the advantages of MLVA - genotyping in comparison with methods based on sequencing of indi- vidual DNA segments (for example, multilocus sequencing typing - MLST) (Pruvost et al., 2011, 2014).

Currently, pulse-field gel electrophoresis (PFGE), based on the digestion of the native genomic DNA of a bacterium by restriction endonucleases with a small number of recognition sites (20-30), is considered to be a highly sensitive method for determining genetic features in the DNA structure (the appearance and disappearance of restriction sites, duplication and separation of DNA segments, movement of mobile elements, etc.). It is referred to as a classic in the genotyping of clinically significant isolates of pathogenic microorganisms (for example, Salmonella spp., Pseudomonas aeruginosa, etc.) (Pappa et al., 2013; Ziebell et al., 2017). Pruvost et al. (2014) studied 100 strains of the genus Xanthomonas (isolated in 1985-2012 from different geographical areas of Bulgaria). Despite the strains' geographical separation, researchers identified only two haplotypes of $X$. vesicatoria and one of X. gardneri. In a recent paper, researchers used PFGE with XbaI and SpeI restriction endonucleases to identify the heterogeneity of Xanthomonas strains (Kizheva et al., 2018). According to Jacques et al. (2016), at present, the genetic and molecular basis for the practical determination of the host range in the genus Xanthomonas has not been sufficiently studied.

The suggested method of genotyping - double digest and selective labeling (DDSL) - of clinical isolates of pathogenic microorganisms P.aeruginosa was not inferior in its discriminatory power, and in some cases even slightly exceeded the PFGE method (Terletskiy et al., 2008). It was also tested for the rapid and accurate identification of collection strains of Bacillus subtilis, which were similar in a number of biological features, but differed in composition of metabolite complexes (Terletsky et al., 2016).

The purpose of this work was to evaluate the DDSL method for representatives of the genus Xanthomonas, isolated from infected samples of several cultivars obtained from geographically distant regions.

\section{Materials and Methods}

The objects of research were strains of phytopathogenic bacteria of the genus Xanthomonas, isolated from infected samples of several crops obtained from geographically remote regions (isolated by us, as well as from other institution collections (Table 1). Eleven strains of Xanthomonas were used: from cabbage (strains 1-7), tomato (strain 8), radish (strain 9), sorghum (strain 10), and begonia (strain 11). We maintained the collection of phytopathogenic bacteria strains in $2 \%$ potato agar in glass tubes by reseeding bacteria every 3-4 months in order to keep their biological properties constant. The studied strains were grown in test tubes with meat-peptone broth for 2 days $\left(25^{\circ} \mathrm{C}\right)$. 
Table 1. Characterization of strains of bacteria of the genus Xanthomonas, presented for genotyping by the DDSL method

\begin{tabular}{|c|c|c|c|}
\hline $\mathrm{N}$ & $\begin{array}{c}\text { Bacterial strain of } \\
\text { Xanthomonas campestris (X. c.) }\end{array}$ & Plant, variety & $\begin{array}{c}\text { Place and year of isolation and separation, } \\
\text { country, institution }\end{array}$ \\
\hline 1 & X.c. pv. campestris P 1 & Cabbage & 2006, Belarus, BELNIIZR \\
\hline 2 & X.c. pv. campestris 8169 & $-\ll-$ & 1984, Ukraine, IMV \\
\hline 3 & X.c. pv. campestris 1305 & $-\ll-$ & 2006, Moscow region, VNIIF \\
\hline 4 & X.c. pv. campestris 1306 & $-\ll-$ & 2006, Moscow region, VNIIF \\
\hline 5 & X. c. pv. campestris Cab 4 & $-\ll-$, Moscow late & 1984, Leningrad region, VIZR \\
\hline 6 & X.c. pv. campestris Cab 7 & $-\ll-$, Moscow late & 1984, Leningrad region, VIZR \\
\hline 7 & X.c. pv. campestris 7604 & $-\ll-$ & 1984, Ukraine, IMV \\
\hline 8 & X. c. pv. vesicatoria 7767 & Tomato & 1984, Ukraine, IMV \\
\hline 9 & X. c. pv. armoraciae 373 & Horse radish & 1960, UK \\
\hline 10 & X.c. pv. holcicola 8954 & Sorghum & 1984, Ukraine, IMV \\
\hline 11 & X.c. spp. 3 & Begonia & 2018, Leningrad region, VIZR \\
\hline
\end{tabular}

The first step in genotyping is DNA isolation, which was performed using standard phenol/chloroform protocol. DNA was precipitated by isopropanol, washed in $70^{\circ}$ ethanol, and dissolved in water. The DDSL method of genotyping is based on the use of two restriction endonucleases for digestion of the bacterial genomic DNA: the first enzyme cuts DNA, forming 3'-recessed fragment ends, and the second one forming 3'-protruding or blunt ends. Present in the reaction mixture, Taq DNA polymerase provides for labeling DNA fragments with biotinylated deoxycytosine triphosphate (Bio-dCTP). The label is incorporated in a fill-in reaction only in DNA fragments that have 3'-recessed ends formed by the first rare cutting enzyme. The second frequently cutting restriction endonuclease generates blunt or 3'-protruding ends of the fragments that are not capable of tagging. This enzyme makes DNA fragments shorter to be suitable for separation in a standard agarose gel. As a result, 20-50 clearly distinguishable DNA fragments, the number and distribution of which is characteristic for each bacterial strain, are visualized on the filter. An in silico search (http://insilico.ehu.eus/digest/) allowed us to propose a combination of genotyping enzymes. As the first enzyme, the restriction endonuclease $B c u I$, which has several dozen cleavage sites in the genomes of the representatives of the genus Xanhtomonas and forms 3'-recessed fragment ends, is the most promising and was used in the first stage of the development of the technique. The second enzyme that digests the DNA of Xanthomonas in more than 1000 sites was the restriction endonuclease Eco147I. The latter generated ends of DNA fragments that are not able to be labeled with biotin. An important criterion for the selection of enzymes is their compatibility in one buffer and appropri- ate number of cleavage sites as mentioned above. In particular, in buffer B (Thermo Fischer Scientific), BcuI is active at 50-100\%; the activity of the Eco147I enzyme in this manufacturer-recommended buffer is $100 \%$. Other enzyme combinations can also be used but in our hands the best data are generated with $B c u I / E c o 147$ I combination. In silico simulation of number of cleavage sites in all sequenced bacterial genomes is available on the website http://insilico.ehu.es/digest/.

Technically, the DDSL reaction is performed in a single mictotube containing $15 \mu \mathrm{H}_{2} \mathrm{O}, 2 \mu$ l buffer $\mathrm{B}$ (Thermo Fischer Scientific), $2 \mu$ l bacterial DNA, and $1 \mu \mathrm{l}$ enzymatic mix. The latter includes $0.5 \mu \mathrm{l}$ of $B c u \mathrm{I}$, and Eco147I each, $1 \mu$ l of Taq polymerase (diluted by water in proportion $1: 10$ ), and $0.5 \mu \mathrm{l}$ of Bio-dCTP per one reaction. Normally, the number of reaction microtubes is more than one, and the amount of preformulated mix is calculated depending on the number of bacterial samples in a given experiment. The reaction is complete within 1 hour at $37^{\circ} \mathrm{C}$. Gel electrophoresis is performed in $0.8 \%$ agarose gel at $60 \mathrm{~V}$ for 16 hours (alternatively, 3 hours is enough at $150 \mathrm{~V}$ ), transfer to nylon filter is carried out in distilled water for 30 minutes immediately after electrophoresis. Detection of biotin-tagged fragments on the filter is based on streptavidin-alkaline phosphatase conjugate chemistry using NBT and BCIP color forming substrates (Thermo Fischer Scientific).

\section{Results}

After theoretical selection (in silico) of enzymes, experiments were carried out with several strains of the genus Xanthomonas. It was found that the selected enzymes form the optimal number of labeled DNA fragments 


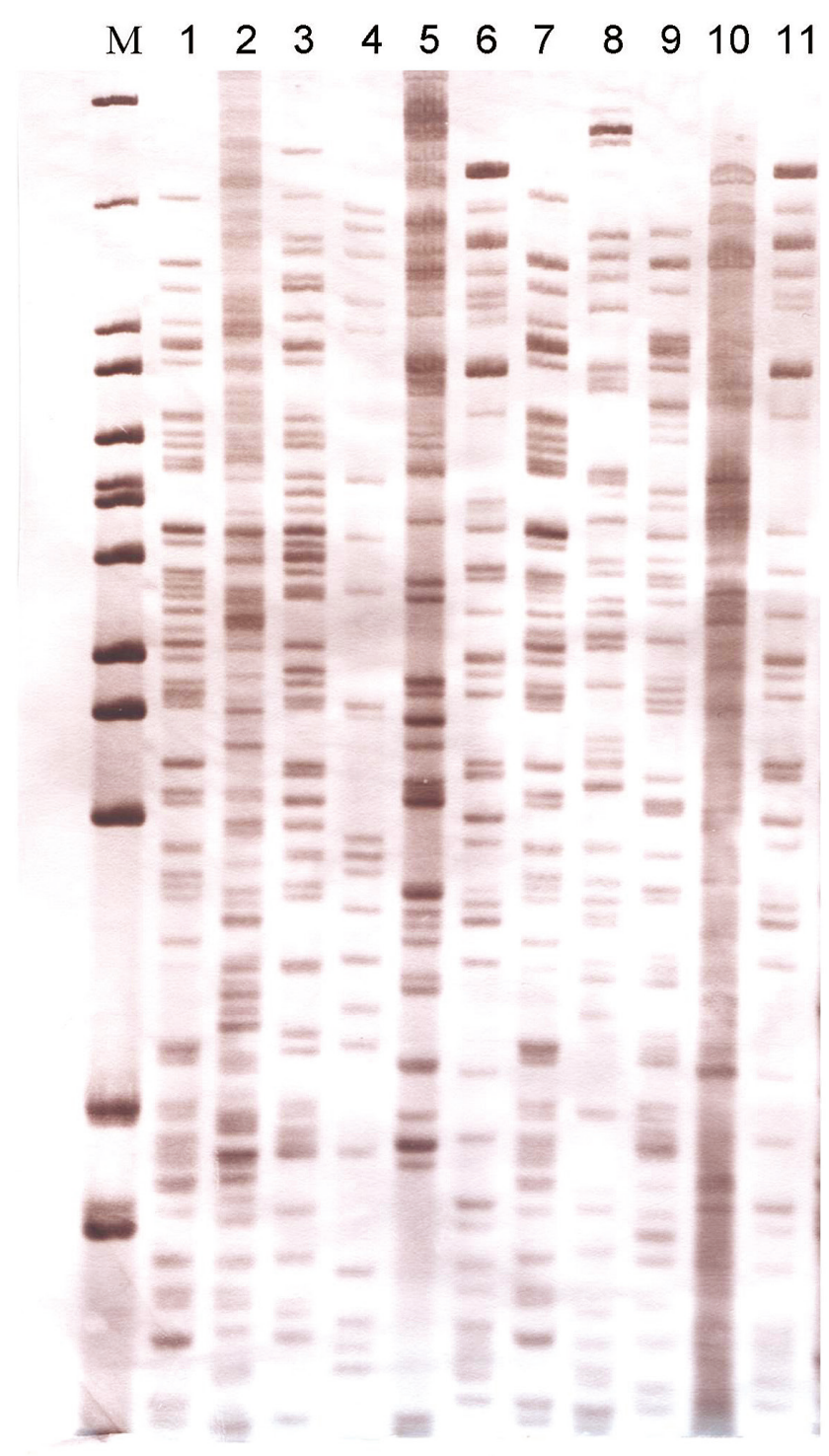

Fig. 1. Genotyping of 11 strains of the genus Xanthomonas by the DDSL method with restriction endonucleases of Bcul/Eco147I

(from 22 to 60 ), which are well separated in a $0.8 \%$ agarose gel. At the next stage of the study, 11 phytopathogenic strains were examined (Figs. 1, 2). Molecular weight marker was lambda DNA digest (HindIII and $B s t$ EI enzymes, tagging of Bio-dCTP in fill-in reaction), the fragment size varied from 23130 to $500 \mathrm{bp}$. The number of common (and different) bands between strains was up to 40 , which made it possible to construct a phylogenetic tree using software package Statistica 6.0. (module Cluster analysis, Euclidian distance). In general, high genetic diversity of the strains was established, and they differed both in the number of detected DNA fragments and in their distribution. This fact emphasizes the high resolution of this method, which was previously demonstrated on several types of pathogenic clinically significant pathogens, as well as phytopathogen antagonistic bacteria (Terletskiy et al., 2016).
Analysis of the distribution of DNA fragments shows that strains 1 and 7 are genetically identical. Both strains were isolated from cabbage grown in different places (Belarus and Ukraine) and their genetic proximity may indicate a common host of these crops or the use of the original planting material from a specific place where the pathogen was further spread. The data on the genotyping of strains 3 and 4 are also interesting (Table 1). Although they were isolated in 2006 from the Vologda leaf cabbage variety plants in the Moscow region, their characteristics differ substantially in almost all DNA fragments. In addition, strain 4 was genetically distant from all other analyzed strains, since it has a relatively small number of DNA fragments. A similar pattern was noted for strains 2 and 7, 5 and 6, which have a common origin (Ukraine, IMV, and Russia, Leningrad region, VIZR, respectively), but are genetically distant from each other.

Analysis of differences in the position of DNA fragments in strains derived from different crops shows that these variants are no more distant from each other than variants from the same plant species. Moreover, it was found that strain 6 (cabbage, Leningrad region, VIZR, 1984 ) is genetically close to strain 11 , obtained from the begonia greenhouse plant (Leningrad region, 2018); the position of most DNA fragments is the same with almost the same number of all fragments in both genomes.

As was expected, various subspecies (for example, strains 8, 9 and 10), despite the geographical proximity of origin, are genetically distant from each other. Strains isolated from other host plants (not cabbage strains) show a specific pattern in terms of the distribution of DNA fragments. In this case, we cannot talk about the transmission of the pathogen between different hosts.

\section{Discussion}

Counting the number of common and differing DNA fragments revealed no association between geographic location and genetic distance between the strains. Analysis of differences in the position of DNA fragments in strains derived from different crops shows that these variants are no more distant from each other than variants from the same culture. The fact that strain 6 (cabbage, Leningrad region, VIZR, 1984) is genetically close to strain 11, obtained from the begonia greenhouse culture (Leningrad region, 2018) can be explained by the probability of transmission through soil, despite a significant time gap in bacteria isolation; the position of most DNA fragments is the same with almost the same number of all fragments in both genomes. This is a relatively rare case when the identity of the strains is noted, despite their geographical and temporal distance and their different host plants. This observation drawn on the base of DDSL data indicates the absence of any relation be- 


\section{Tree Diagram for 11 Xanthomonas strains Single Linkage Euclidean distances}

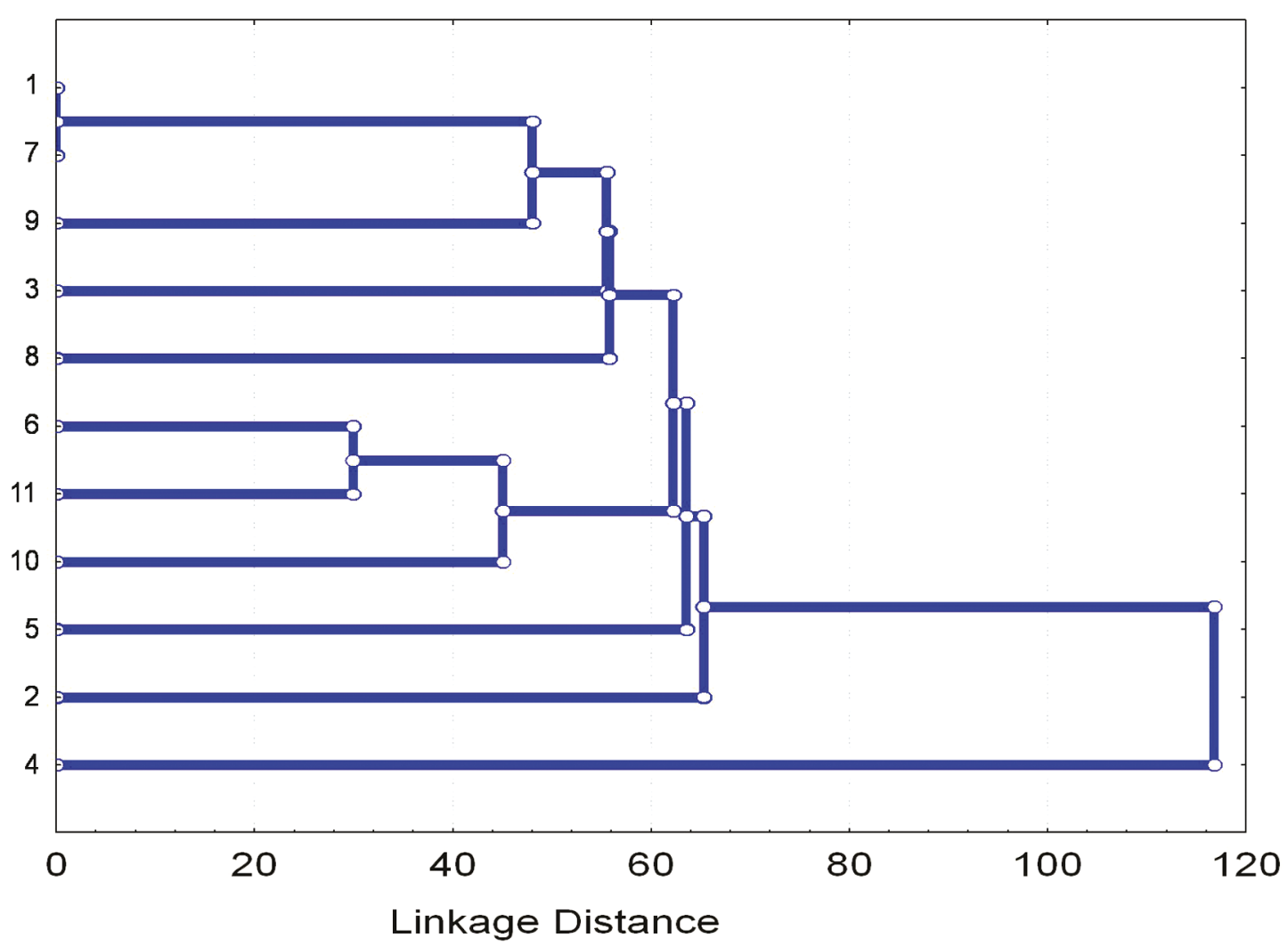

Fig. 2. Dendrogram of genetic relationships between bacterial strains of the genus Xanthomonas

tween the pathogen genotype and the host plant species, and underlines that pathogens of this kind are able to infect a wide range of different plants. Prolonged storage of bacterial culture in collection did not affect the genetic structure, as can be seen in strains 6 and 11 collected in 1984 and 2018 from the same source. So, we can assume a slow rate of accumulation of mutations during reseeding. The same slow rate we observed in Salmonella spp. when we used LT2 reference strains kept in a Spanish hospital collection for more than 50 years. Only a few differences in genetic profiles were detected.

Thus, it has been shown that the DDSL method, tested on a number of strains of the genus Xanthomonas, isolated from different crops, allows us to prove the transmission of the pathogen between hosts and show the specific prevalence of individual strains of phytopathogens among crops. It shows the possibility of identifying and unambiguously identifying strains of phytopathogenic bacteria of this kind in the process of phytosanitary monitoring during the development of epiphytoties of potato bacteriosis. The fundamentals of the developed technique for genotyping pathogens in pure culture of the Xanthomonas genus bacteria will fur- ther help to identify them in samples of plant material with characteristic symptoms of the disease and in the form of latent infection, which will make it possible to effectively plan phytosanitary measures for growing and storing agricultural plant products.

As DDSL technique is based on a simple restriction digestion of genomic DNA and simultaneous fragment labeling, the generated genetic profiles are highly reproducible. Taq polymerase is still able to incorporate a single Bio-dCTP molecule into 3'-recessed fragment ends at $37^{\circ} \mathrm{C}$, the observation that makes it possible to perform digestion and labeling in a single reaction mictotube at this temperature.

\section{References}

Barak, J. D. and Glibertson, R. L. 2003. Genetic diversity of Xanthomonas capestris pv. vitians, the causal agent of bacterial leafspot of lettuce. Phytopathology 93(5):596-603. https://doi.org/10.1094/PHYTO.2003.93.5.596

Bui, T. N., Veniera, C., Jarne, P., Brisse, S., Guerin, F., Boutry, S., Gagnevin, L., and Puvost, O. 2009. From local surveys to global surveillance: three high-throughput genotyping methods for epidemiological monitoring of Xanthomonas citri pv. citri pathotypes. Applied and Environmental 
Microbiology 75(4):1173-1184. https://doi.org/10.1128/ AEM.02245-08

Ignatov, A., Sechler, A., Schuenzel, E. L., Agarkova, I., Oliver, B., Vidaver, A. K., and Schaad, N. W. 2007. Genetic diversity in populations of Xanthomonas campestris pv. campestris in cruciferous weeds in central coastal California. Phytopathology 97(7):803-812. https://doi.org/10.1094/ PHYTO-97-7-0803

Jacques, M.-A., Arlat, M., Boulanger, A., Boureau, T., Carrère, S., Cesbron, S., Chen, N. W. G., Cociancich, S., Darrasse, A., Denancé, N., Fischer-Le Saux, M., Gagnevin, L., Koebnik, R., Lauber, E., Noël, L. D., Pieretti, I., Portier, P., Pruvost, O., Rieux, A., Robène, I., Royer, M., Szurek, B., Verdier, V., and Vernière, C. 2016. Using ecology, physiology, and genomics to understand host specificity in Xanthomonas. Annual Review of Phytopathology 54:163-187. https://doi.org/10.1146/annurev-phyto-080615-100147

Kizheva, Y., Urshev, Z., Rasheva, I., Vancheva, T., Hristova, P., Bogatzevska, N., and Moncheva, P. 2018. PFGE: a tool for examination of heterogeneity between the bacterial spot-causing xanthomonads of tomato plants in Bulgaria. Zeitschrift für Naturforschung C 73(7-8):257-264. https://doi.org/10.1515/znc-2016-0205

Lopez, R., Asensio, C., and Gilbertson, R. L. 2006. Phenotypic and genetic diversity in strains of common blight bacteria (Xanthomonas campestris pv. phaseoli and X. campestris pv. phaseoli var. fuscans) in a secondary center of diversity of the common bean host suggests multiple introduction events. Phytopathology 96(11):1204-1213. https://doi.org/10.1094/PHYTO-96-1204

Mansfield, J., Genin, S., Magori, S., Citovsky, V., Sriariyanum, M., Ronald, P., Dow, M., Verdier, V., Beer, S. V., Machado, M. A., Toth, I., Salmond G., and Foster, G. D. 2012. Top 10 plant pathogenic bacteria in molecular plant pathology. Molecular Plant Pathology 13:614-629. https:// doi.org/10.1111/j.1364-3703.2012.00804.x

Oguniobi, A. A., Fagade, O. E., and Dixon, A. G. 2010. Comparative analysis of genetic variation among Xanthomonas axonopodis pv. manihotis isolated from the western states of Nigeria using RAPD and AFLP. Indian Jour- nal of Medical Microbiology 50(2):132-138. https://doi. org/10.1007/s12088-010-0037-6

Pappa, O., Mandilara, G., Vatopoulos, A., and Mavridou, A. 2013. Typing of Pseudomonas aeruginosa strains isolated from Greek water samples by three typing methods: serotyping, Random Amplified Polymorphic DNA (RAPD) and Pulsed Field Gel Electrophoresis (PFGE). Water Science and Technology 67(6):1380-1388. https://doi. org/10.2166/wst.2013.678

Pruvost, O., Magne, M., Boyer, K., Leduc, A., Tourterel, C., Drevet, C., Ravigne, V., Gagnevin, L, Guerin, F., Chiroleu, F., Koebnik, R. Verdier, V., and Verniere, C. 2014. A MLVA genotyping scheme for global surveillance of the citrus pathogen Xanthomonas citri pv. citri suggests a worldwide geographical expansion of a single genetic lineage. PLOS ONE 9(6):e98129. https://doi.org/10.1371/journal.pone.0098129

Pruvost, O., Vernière, C., Vital, K., Guérin, F., Jouen, E., Chiroleu, Ah-You, N., and Gagnevin, L. 2011. Insertion sequence- and tandem repeat-base genotyping techniques for Xanthomonas citri pv. mangiferaeindicae. Phytopathology 101(7):887-893. https://doi.org/10.1094/ PHYTO-11-10-0304

Terletskiy, V., Kuhn, G., Francioli, P., and Blanc, D. 2008. Application and evaluation of double digest selective label (DDSL) typing technique for Pseudomonas aeruginosa hospital isolates. Journal of Microbiological Methods 72:283-287. https://doi.org/10.1016/j.mimet.2007.12.006

Terletsky, V. P., Tyshchenko, V. I., Novikova, I. I., Boykova, I. V., Tyulebayev, S. D., and Shakhtamirov, I. Ya. 2016. An effective method of genetic certification of Bacillus subtilis strains - promising producers of biological preparations. Microbiology 85(1):50-55. (In Russian) https://doi. org/10.7868/S0026365616010134

Ziebell, K., Chui, L., King, R., Johnson, S., Boerrlin, P., and Johnson R. P. 2017. Subtyping of Canadian isolates of Salmonella Enteritidis using Multiple Locus Variable Number Tandem Repeat Analysis (MLVA) alone and in combination with Pulsed-Field Gel Electrophoresis (PFGE) and phage typing. Journal of Microbiological Methods 139:2936. https://doi.org/10.1016/j.mimet.2017.04.012 